\title{
EM QUE SENTIDO A VIRTUDE É MAIS EXATA QUE A TÉCNICA? NOTAS SOBRE ETHICA NICOMACHEA 1106B 14-16
}

\author{
Lucas Angioni \\ UNICAMP
}

\begin{abstract}
This paper examines what Aristotle could have meant in Nicomachean Ethics 1106b 14-16, when he says that moral virtue is more exact than craft. Aristotle's meaning cannot be that moral knowledge is more exact than technical knowledge. Neither the practical knowledge that an agent has about the precepts guiding his actions nor the philosophical knowledge framed in a moral theory could be described as "more exact than craftknowledge". My point is that Aristotle's meaning is better understood if he is taken to be talking about the requirements for doing virtuously a virtuous action. Being successful at doing a virtuous action is "more exact" than being successful at making a good craft-product in the sense that more criteria for successfulness are required.
\end{abstract}

Keywords: Moral virtue, excellence of character, psychology of action, teleology, ethics.

Resumo: Este artigo busca compreender o que Aristóteles quer dizer em Ethica Nicomachea 1106b 14-16, ao afirmar que a virtude moral é mais exata do que a técnica. Aristóteles não pode querer dizer que o conhecimento moral (seja o conhecimento que um dado agente tem sobre os preceitos que determinam como ele deve agir, seja o conhecimento do filósofo que propõe uma teoria moral) é mais exato que o conhecimento técnico. Tento mostrar que a comparação de Aristóteles deve ser entendida em outro sentido: a realização virtuosa de um ato virtuoso é mais exata no sentido de que exige a satisfação de um conjunto de critérios que são muitos mais complexos que os critérios que permitem discernir um bom produto técnico.

Palavras-chave: Virtude moral, psicologia da ação, ética, moral, teleologia.

Em EN II 6, 1106b 14, Aristóteles afirma que a virtude é mais exata do que a técnica, bem como melhor que a técnica. A primeira metade dessa afirmação, no entanto, é surpreendente por várias razões, e não é muito fácil 
atinar exatamente com o propósito de Aristóteles. O primeiro sentimento do leitor talvez seja de espanto: "do que Aristóteles está falando?"1 Como argumenta Broadie, 2002, p. 304, é óbvio que diversas técnicas requerem um grau de exatidão (ou precisão) que parece não se poder encontrar em matéria de virtude moral. Mas até mesmo esse argumento, que justificaria a surpresa e o espanto do leitor, requer maior precisão, pois ele é vago e pode querer dizer duas coisas bem distintas. Por um lado, o modo mais imediato de compreender o texto nos levaria a julgar que, ao falar de "técnica", neste contexto, Aristóteles está a falar do conhecimento técnico, pelo qual o artífice tem a capacidade de instilar em um material adequado as propriedades que distinguem seu produto. Ou seja, Aristóteles estaria a falar do saber-fazer que configura, por exemplo, a arte da carpintaria, entendido como um conjunto de proposições que descrevem objetos e prescrevem procedimentos de intervenção em materiais apropriados, etc. Nesse caso, dado que Aristóteles introduz uma comparação entre técnica e virtude, seríamos levados a julgar que "virtude", nesse contexto, estaria a designar o conhecimento moral pelo qual um agente tem a capacidade de "produzir" aquilo que ele deve "produzir", isto é, "virtude" designaria o conhecimento com o qual o agente perpetra ações virtuosas ${ }^{2}$. Antes de examinar as dificuldades dessa interpretação, mencionemos a outra opção.

Em Física II 1, 193a 31-36, Aristóteles atesta certo uso ordinário do termo "técnica" pelo qual se designa um produto da técnica. Trata-se, obviamente, de uso metafórico, pois não se pretende dizer que o produto da técnica seria um saber-fazer etc. Não obstante, trata-se de um uso sedimentado na linguagem ordinária ${ }^{3}$. Poder-se-ia argumentar que "técnica" em 1106b 14 teria esse sentido. Mas talvez não seja necessário assumir desse modo essa outra opção interpretativa. Basta dizer que, ao usar o termo

\footnotetext{
${ }^{1} \mathrm{E}$ não há dúvida de que Aristóteles está a falar da virtude moral, mas não de qualquer virtude, pois ele mesmo se encarrega de enfatizar esse ponto, em 1106b 16.

2 Não preciso discutir, nos limites deste artigo, a questão de saber qual seria a importância do conhecimento, em sentido estrito, na "produção" de ações virtuosas. Aristóteles certamente rejeita a tese de que o conhecimento moral seria causa suficiente para engendrar ações virtuosas. De fato, entre as condições requisitadas para a prática da ação virtuosa, Aristóteles inclui o conhecimento, mas como a mais fraca das condições (1105b 2-3). Mas essa discussão não afetará meu ponto, dado que, a rigor, rejeitarei essa primeira possibilidade de intepretar o sentido da comparação entre virtude e técnica.

${ }^{3}$ Para mais detalhes, ver meus comentários a 193a 31-33, em Angioni, 2009. Em português (bem como em grego), diante de um artefato muito bem feito, que exemplifica de modo excelente o bom uso da técnica pertinente, pode-se exclamar: "isso (é que) é técnica!" Em alguns casos, a mesma palavra pode ser usada para a arte e para o objeto de arte (como "pintura", "escultura"), mas mesmo nos casos em que isso não ocorre, pode-se dizer, diante de uma mesa excelentemente fabricada: "isso (é que) é marcenaria!"
} 
"técnica" em 1106b 14, Aristóteles tem em vista, de algum modo, esse uso mais ordinário do termo. Suponha-se, assim, que o foco de Aristóteles não incidiria sobre duas disposições da alma (técnica e virtude), mas sobre os "produtos" ou "resultados" (erga) que essas disposições são capazes de engendrar. Ou melhor: suponha-se que o foco de Aristóteles seja examinar de que modo os requisitos para o engendramento desses resultados (os produtos da técnica, de um lado, e as ações virtuosas, de outro) exigem certas condições das disposições aptas a engendrá-los. Nesse caso, a comparação entre técnica e virtude, longe de introduzir uma comparação entre conhecimento técnico e conhecimento moral, ou longe de introduzir uma comparação entre conhecimento técnico e disposição para agir fundada na escolha (hexis praktike kai prohairetike), entendidas como causas eficientes em seus respectivos domínios, introduziria uma comparação entre as condições requisitadas para a produção de um artefato e as condições requisitadas para a prática de uma ação virtuosa.

Passarei agora a examinar essas duas opções de interpretação.

Ora, a primeira opção envolve várias dificuldades. De fato, Aristóteles diz, várias vezes ao longo da Ethica Nicomachea, que o conhecimento moral de um agente carece de exatidão. Nesses passos, Aristóteles certamente se refere ao modo pelo qual um agente virtuoso organiza suas máximas de ação ${ }^{4}$. Já no início da Ethica Nicomachea, em 1094b 22-23, Aristóteles anuncia que não se deve esperar exatidão quando o assunto é ética (ou, mais precisamente, as coisas belas e justas, que a ciência política tem por objeto). Aristóteles diz que nos devemos contentar, nesse domínio, com verdades que tenham sido mostradas ou provadas de modo compactado e grosseiro (pachulôs), como em um esboço geral (tupôi $)^{5}$, e como se fossem verdadeiras apenas no mais das vezes (hôs epi to polu) ${ }^{6}$. A compreensão exata e detalhada desse passo não é assim tão simples como se poderia julgar pela sua retórica

\footnotetext{
${ }^{4}$ Não estou a dizer que Aristóteles se refere apenas a isso, mas que Aristóteles certamente se refere também a isso, entre outras coisas, o que basta para o meu ponto. Broadie, 2002, p. 265, parece julgar que Aristóteles refere apenas a isso.

${ }^{5}$ Cf. Irwin, 1999, p. 174; Broadie, 2002, p. 265.

${ }^{6}$ Taylor, 2007, p. 66-72, muito acertadamente observa que a característica de "ser verdadeira no mais das vezes" não depende das duas anteriores, isto é, da característica de ser compactada, como um esboço geral. De fato, mesmo a definição de eudaimonia em 1098a 16-18 é um esboço geral, a ser complementado por especificações mais precisas (cf. 1098a 20-22). Acrescento que aquilo que é vago não deixa de ser verdadeiro. Quando vejo alguém saboreando um prato delicioso e pergunto "o que você está comendo?"; se o fulano responde-me "comida!", devo obviamente ficar irritado com a vagueza sarcástica da resposta, mas não posso dizer que a resposta é falsa.
} 
sedutora $^{7}$. Mas basta, para meu argumento, um ponto mínimo, que muito provavelmente pode ser estabelecido para além das controvérsias sobre detalhes. Eis o ponto: entre outras coisas, Aristóteles está a dizer que eventuais máximas, pelas quais um agente virtuoso tentasse guiar seu comportamento moral, não teriam jamais à precisão que vigora nas matemáticas. Tais máximas consistem em generalizações úteis para orientar o comportamento do agente, mas elas têm de ser suplementadas pela consideração dos fatores relevantes em cada circunstância singular, e essa consideração, que é da alçada da phronesis $^{8}$, não pode jamais ser "antecipada" por um sistema de regras precisas e determinadas. O mesmo ponto se confirma em Ethica Nicomachea 1104a 1-10: qualquer teoria, bem como qualquer preceito ${ }^{9}$, sobre as ações não comporta exatidão, de modo que os agentes devem examinar, a cada nova circunstância, os fatores relevantes (ta pros ton kairon). Por outro lado, Aristóteles ressalta que determinar de modo preciso a mediedade, em cada circunstância singular, é tarefa bem difícil (cf. 1109a 24-30). O “conhecimento prévio" de que o agente virtuoso dispõe, para tal efeito, é absolutamente insuficiente: por mais que ele possa recolher generalizações confiáveis, por mais que ele confie nas "opiniões dos homens experientes, mais velhos e sensatos (ou prudentes)" (1143b 11-13), ele não elimina a dificuldade de discernir, em cada caso, como a mediedade deve ser realizada (cf. 1109b 14-23) ${ }^{10}$.

Tudo isso torna bem inverossímil a primeira opção de interpretação. De fato, se o conhecimento moral à disposição de um agente virtuoso é tão precário, se ele jamais escapa da generalidade imprecisa e é sempre insuficiente para discernir o que deve ser feito em cada ação singular, etc., como poderia Aristóteles afirmar que tal conhecimento é mais exato do que o conhecimento técnico?

\footnotetext{
7 Ver Irwin, 1996.

${ }^{8}$ Cf. 1141b 14-22, 1142a 23-25.

${ }^{9}$ Meu ponto também não depende de decisões drásticas a respeito do sentido exato de "logos" em 1104a 1, 3, 5, 6: julgo que "teoria" ou "discurso" capta bem o sentido no contexto, mas, se alguém prefere julgar que "logos" em 1104a 6 deve ser entendido no sentido de "preceito" ou "máxima", isso não afeta o meu ponto. Rowe traduz de modo bem geral, compatível com ambas as interpretações, embora talvez mais próximo da noção de "teoria sobre as ações", em vez de "preceitos para as ações". Zingano, 2008, p. 104, favorece a noção de discurso sobre o que devemos fazer em tal e tal circunstância. Mas ressalte-se que, se se opta por "teoria", deve-se esclarecer que não se trata de todas as proposições que constituem a teoria ética (pois muitas delas são exatas, precisas e verdadeiras sempre), mas apenas as proposições sobre ações.

${ }^{10} \mathrm{Cf}$. 1164b 27-30.
} 
A segunda opção interpretativa consiste em tomar o contraste entre "técnica" e "virtude" como um contraste entre as condições requisitadas para o engendramento dos respectivos resultados que cada uma deve produzir, ou seja, um contraste entre as condições requisitadas para a produção de artefatos e as requisitadas para a prática de ações virtuosas. Nessa perspectiva, a afirmação de que "a virtude é mais exata que a técnica" deveria ser entendida do seguinte modo: para a prática de uma ação virtuosa, deve-se observar um conjunto de requisitos que são muito mais numerosos e/ou muito mais exigentes do que os requisitos a serem observados para a produção de um artefato. $O$ grau de exigência dos requisitos a serem observados na ação virtuosa daria a esta última certa "exatidão".

Em favor dessa interpretação, temos duas ordens de razões. Por um lado, julgo que o resultado teórico de tal interpretação faz pleno sentido no quadro da ética aristotélica como um todo. Por outro lado, do ponto de vista exegético, essa interpretação permite uma leitura coerente do passo no contexto do argumento do livro II da Ethica Nicomachea, de modo que a afirmação controversa de Aristóteles pode surgir como bem encaixada em seu contexto. Argumentarei, em seguida, em favor desses dois pontos. Seria possível tomar as razões filosóficas e as exegéticas paralelamente, ou mesmo de modo independente. No entanto, é mais propício para meu argumento considerar, de início, o primeiro texto em que ele se poderia fundar do ponto de vista exegético.

Em 1105a 26- b 5, Aristóteles compara cuidadosamente as condições sob as quais se engendra um "resultado da técnica", isto é, um produto, e as condições sob as quais se engendra uma ação virtuosa. Essa comparação é motivada por uma possível dificuldade que poderia emergir da argumentação anteriormente empreendida no livro II. Aristóteles insistiu em mostrar que a virtude moral não é uma capacidade natural (como a sensação, cf. 1103a 2632), tampouco é adquirida por nós graças a algum processo natural. A virtude moral engendra-se em nós pela prática repetida ou habitual das mesmas ações que ela será capaz de produzir ${ }^{11}$. Tudo que Aristóteles quer dizer é que a prática habitual dessas ações é condição apenas necessária, mas não suficiente, para engendrar a virtude moral no agente que as pratica. Mas sua exposição foi, de fato, um pouco vaga e poderia sugerir a tese (que ele claramente rejeita) de que o hábito de praticar tais ações seria condição

${ }^{11}$ Cf. 1103a 31- b 2, 1103b 14-22, 1104a 33-b 3, 1105a 14-16. 
suficiente para o agente se tornar virtuoso. De modo similar, seu argumento foi vago o bastante para suscitar o aparente paradoxo formulado em 1105a 17-21: se o agente pratica atos virtuosos, ele já seria virtuoso, de modo que não teria por que se habituar a praticá-los para vir a adquirir a virtude, pois ele já a teria. Parece que o problema seria o seguinte: como o agente, antes de adquirir a virtude e ser virtuoso, poderia praticar atos virtuosos? Esse problema assume como pressuposto a tese de que ser um agente virtuoso seria condição necessária para praticar atos virtuosos, bem como a tese complementar de que praticar atos virtuosos seria condição suficiente para ser virtuoso. Aristóteles, no entanto, rejeita essas duas teses, de modo sutil: ele introduz uma distinção entre dois modos de se entender a expressão "praticar atos virtuosos". Tal expressão pode referir-se a atos que têm apenas as feições externas de um ato virtuoso, ou pode referir-se a atos que são virtuosos no sentido pleno, porque satisfazem também uma série de condições "internas" do agente, as quais se adicionam às condições externas ${ }^{12}$. É nesse contexto que surge a comparação que nos interessa.

Aristóteles diz que os produtos da técnica têm seu bom estado e, podemos dizer, sua excelência (to eu) em si mesmos (1105a 27-28). Para que eles contem como "bons produtos" e para que se possa dizer que eles são boas realizações da técnica, basta que eles tenham em si mesmos, certas propriedades. O que Aristóteles quer ressaltar será elucidado por contraste com o caso das ações virtuosas: Aristóteles quer ressaltar que, para que um produto seja considerado um "bom produto", são irrelevantes as eventuais vicissitudes de sua produção. Mas o mesmo não se passa com os "resultados" que a virtude moral deve produzir. Neste caso, as coisas que se engendram pela virtude moral, isto é, as ações virtuosas, contam como "ações virtuosas" e como "produtos da virtude" somente se certas condições forem acrescentadas (1105a 28-30). Uma ação tem várias propriedades "externas": todas as propriedades que poderiam ser descritas por um observador que não teria acesso pleno às condições psicológicas do agente. Essas propriedades são análogas às propriedades que os produtos da técnica têm em si mesmos. No entanto, ações não podem ser contadas como "virtuosas” em sentido estrito tendo por base tão apenas essas propriedades externas. Ações contam como virtuosas em sentido estrito se outros três requisitos forem satisfeitos: (i) o agente deve ter conhecimento daquilo que faz, isto é, deve considerar sua

12 O mesmo ponto é exposto por Aristóteles em EN 1144a 13-20, bem como em 1137a 4-25. 
ação sob a descrição relevante do ponto de vista moral; (ii) o agente deve ter escolhido tal ação, ou melhor, deve tê-la escolhido pelo seu valor moral intrínseco; (iii) o agente deve ter praticado a ação sem conflito interno ${ }^{13}$.

Ainda que muitas controvérsias possam ser suscitadas quanto aos detalhes de interpretação dessas três condições, depreende-se delas um ponto incontroverso, que basta para meu argumento: há uma disparidade entre os requisitos que um "bom produto" deve satisfazer e os requisitos que uma "ação virtuosa” deve satisfazer. Um "bom produto" é definido pela satisfação de certas propriedades, que o habilitam a desempenhar bem sua função. Um bom serrote é aquele que desempenha bem a função de serrar madeira e, para o bom desempenho dessa função, ele deve apresentar certas propriedades relevantes, relativas à sua constituição material (ele não pode ser feito de lã, nem de madeira, por exemplo, mas deve ser feito de ferro ou bronze ${ }^{14}$ ), a sua configuração (deve ter dentes de tal e tal tipo ${ }^{15}$ ), à disposição recíproca das partes (o cabo e a lâmina não podem ser desproporcionais entre si), etc. Também uma "ação virtuosa" pode ser definida por referência ao bom desempenho da função do agente (cf. 1106a 15-24): conta como "ação virtuosa" aquela na qual o agente demonstra bom desempenho no exercício de sua função enquanto ser humano ${ }^{16}$. No entanto, para o bom desempenho da função do agente, não basta que a ação satisfaça certas características "externas”, é preciso que ela satisfaça também uma série de condições internas, que dizem respeito à disposição psicológica do agente.

${ }^{13}$ Não afeta o meu ponto as divergências de interpretação dessas três condições dadas em 1105a 3033. Muitos interpretam a condição (iii) de modo bem diferente (Broadie, 2002, p. 19: "firm and unchanging disposition"; Taylor, 2007, p. 84: "a stable and unchangeable state of character"). Essa diferença não interfere no modo pelo qual se pode entender que a virtude seria mais "exata" que a técnica. No entanto, não posso deixar de notar que não vejo absolutamente nenhuma evidência para julgar que a condição (iii) refere-se à trajetória transtemporal do agente, que teria o caráter "estável e imutável" ao longo do tempo. Ora, o que Aristóteles quer dizer é que o agente virtuoso, ao praticar virtuosamente a ação virtuosa, deve agir com firmeza e sem atribulações internas, sem conflito interno. O contraste é claramente com o continente (por exemplo), ou com alguém que decide praticar a ação justa e a escolhe por seu valor moral intrínseco, mas escolhe e pratica tal ação depois de muito considerar ou bem a possibilidade de praticar 0 ato injusto (que the traria alguma vantagem) ou bem uma justificativa inadequada para 0 ato justo (como 0 aumento de seu prestígio social). Zingano, 2008, p. 117, assume posição circunspecta sobre essa terceira condição. Minha interpretação não nos obriga a dizer que fulano que se dilacerou em um dilema moral e praticou heroicamente sua primeira ação justa (por exemplo) não pratica uma ação justa. Ela praticou uma ação justa, mas ainda não a praticou justamente.

${ }^{14}$ Cf. Metafísica 1044a 28-29, Física 200b 7, As partes dos animais 642a 9-11.

${ }^{15} \mathrm{Cf}$. Física 200b 6.

${ }^{16}$ Cf. 1098a 7-15. Não preciso entrar nos detalhes de interpretação sobre o que conta como ergon do homem. 
Tudo isso prova, no entanto, que os requisitos que a ação virtuosa deve atender são mais numerosos e mais complexos do que os requisitos que o produto da técnica deve atender. Mas nada disso prova que esses requisitos mais numerosos e mais complexos redundam em uma maior exatidão da virtude em comparação com a técnica. Passo, então, a argumentar em favor desse ponto: os requisitos mais complexos da ação virtuosa são tais que a virtude, em certo sentido, pode ser tomada como algo "mais exato" que a técnica.

O princípio do meu argumento continua a ter como foco o contraste entre ações virtuosas e produtos técnicos. No contexto do livro II da $E N$, realizar uma ação virtuosa é algo comparável a acertar o alvo, e acertar o alvo quer dizer acertar a justa medida ou a mediedade17 ("meson"). Também para as técnicas, realizar bem o produto consiste em acertar a justa medida (cf. 1106a 8-9). Ora, em que condições podem acertar a justa medida, na ação virtuosa e na produção técnica? Quais são os requisitos para acertar o alvo, em cada caso?

Creio que se pode dizer que os requisitos são muito mais apurados e precisos na ação virtuosa do que na produção técnica. Em 1106b 28-31, Aristóteles diz, em relação à justa medida em que residem às ações virtuosas, que é possível errá-la de vários modos, mas é possível acertá-la apenas de um modo. Talvez essa oposição entre erros múltiplos e acerto único seja um exagero retórico, mas a tese básica de Aristóteles persiste: "é fácil errar, mas é difícil acertar: é fácil errar o alvo, é difícil acertá-lo” (1106b 31-33) ${ }^{18}$.

Por que, segundo Aristóteles, é difícil acertar a justa medida na ação virtuosa? Em primeiro lugar, é difícil acertá-la porque ela envolve uma série de fatores. A justa medida requer, conjuntamente, o tempo oportuno, os motivos adequados, os objetos adequados, os agentes adequados, os propósitos adequados, a intensidade correta, o modo correto etc. (cf. 1106b 21-22). Em segundo lugar, não bastasse o número desses fatores, há que

\footnotetext{
17 Cf. 1106b 31-33.

18 Talvez seja verdade dizer que, para o conjunto de todos os seres humanos, se todos tentassem fabricar uma cama, os erros seriam múltiplos (erros cometidos por todos os que não têm a técnica relevante), mas os acertos seriam poucos (pois seriam restritos à classe dos marceneiros). No entanto, creio que o mais correto é tomar como referência, na comparação entre virtude moral e técnica, 0 conjunto dos homens dotados de competência técnica (não o conjunto de todos os homens). Seria razoável dizer que, entre os marceneiros, em suas tentativas de produzir camas, os erros seriam mais numerosos que os acertos? Uma afirmação como essa parece não ter lugar, a não ser que se tome por referência aprendizes de marceneiro, no início do aprendizado.
} 
considerar ainda o fato de todos eles serem fatores singulares, que caem sob a alçada da percepção (cf. 1109b 22-23). Pelas razões a que aludi na primeira parte deste artigo, é evidente que o cômputo adequado desses fatores singulares é algo bem difícil, que escapa a qualquer generalização. Para avaliar a relevância desses fatores, qualquer preceito geral é apenas um parâmetro vago e insuficiente.

No entanto, é justamente esse ponto que permite elucidar a "exatidão" da ação virtuosa. Os fatores singulares que envolvem uma ação virtuosa estão no domínio de uma contingência que escapa a qualquer previsibilidade. Não há máxima geral que seja suficiente para discernir como esses fatores devem ser avaliados. Mas, justamente por serem contingentes e imprevisíveis, esses fatores devem ser cuidadosamente avaliados e considerados pelo agente, e qualquer descuido pode resvalar da justa medida para o excesso e a falta ${ }^{19}$.

Compare-se com a cama fabricada por um marceneiro. Os fatores mencionados em 1106b 21-22 (motivos, objetos, oportunidades, agentes envolvidos, etc.) têm relevância muito menor. É claro que são devidamente relevantes todos os fatores que interferem no bom desempenho funcional da cama. Assim, faz diferença construir uma cama para crianças ou uma cama para adultos obesos etc. Mas não faz diferença, para o marceneiro, isto é, para o bom desempenho da sua atividade produtiva, discernir os motivos pelos quais se encomendou a cama (cama "extra" para visitas ou reposição de cama imprestável?), os usos que farão da cama, o modo pelo qual usarão a cama (se vão dormir sete ou dez horas por noite etc.). Mais importante ainda é a irrelevância das disposições psicológicas do marceneiro: se ele faz a cama das dez às quatorze horas, ou das doze às dezesseis; se ele faz a cama apenas para

\footnotetext{
19 Talvez um exemplo seja elucidativo. Tomemos um caso que diz respeito à generosidade. Fulano está parado no semáforo e é abordado por uma criança maltrapilha que the pede esmolas. Embora as aparências sugiram que a criança realmente está a necessitar de ajuda material para comer etc., há vários fatores a serem levados em conta. Há notícias de que quadrilhas de traficantes adultos usam crianças maltrapilhas para recolher dinheiro. Há notícias de que a quadrilha fixa uma quantia mínima a ser arrecadada por cada criança, diariamente. Se a criança não entregar tal quantia para os traficantes ao final do seu turno, será espancada. Com todas essas informações, fulano avista um adulto em atitude suspeita, a observar a ação da criança. Ao mesmo tempo no carro ao lado, o colega de trabalho que acusou fulano de ser pão-duro o observa com interesse sarcástico. Etc. Isso basta, creio, para mostrar a complexidade dos fatores singulares que envolvem uma ação que se pretende virtuosa. Uma motivação errada (por exemplo, dar esmolas para refutar a acusação do colega sarcástico), bem como uma interpretação errada das informações disponíveis, basta para conspurcar o caráter virtuoso da ação. Aristóteles talvez exagere em sua retórica, ao dizer que há apenas um acerto. Mas seu ponto principal é claro. A complexidade dos fatores singulares conferem à ação virtuosa precisão, no sentido de que, se as circunstâncias fossem outras, a mesma ação dificilmente poderia ser considerada como virtuosa.
} 
obter seu sustento, ou também por prazer; se ele faz a cama com o propósito de impressionar seu cliente; se ele faz a cama de mal-humor; se ele odeia o cliente que fez a encomenda, etc., enfim, todos esses fatores tornam-se irrelevantes, diante das propriedades objetivas que ele instilou no seu produto. Para que seu produto seja apreciado como um "bom produto", basta considerar as propriedades da cama em si mesma, sem nenhuma atenção aos fatores psicológicos que envolveram as vicissitudes de sua produção.

O resultado disso é o seguinte: é mais fácil "acertar a justa medida" pela qual se define uma boa cama do que "acertar a justa medida" pela qual se define uma ação virtuosa. Afinal, a contingência da matéria envolvida na produção de uma cama é muito mais restrita do que a contingência dos inúmeros fatores envolvidos na prática de uma ação virtuosa. Se o marceneiro constrói uma excelente cama, mas teve desprazer no processo de produção porque a encomenda foi feita por um inimigo, pouco importa. Mas, se um agente pratica uma ação justa (isto é, "externamente justa”) com imenso desprazer, por estar a perder dinheiro em tal ocasião, não se diria que ele praticou a ação justa de modo justo e, portanto, não se diria que ele praticou uma ação virtuosa no sentido pleno da expressão.

Voltemos ao nosso ponto de partida. Parece surpreendente que Aristóteles afirme que a virtude moral é mais exata do que a técnica, dado que o conhecimento técnico parece ser muito mais determinado do que o conhecimento moral das máximas e preceitos que orientam a conduta de um agente virtuoso. Aristóteles freqüentemente afirma que nosso conhecimento moral é vago e impreciso, e isso pode ser tomado de dois modos. Por um lado, são vagos e imprecisos os preceitos e as máximas pelos quais um agente virtuoso guia sua conduta. Por outro, são vagos e imprecisos os discursos que se podem fazer, no plano teórico, para descrever e tentar explicar em que consistem as virtudes morais. No entanto, a vagueza, a inexatidão e a imprecisão no plano teórico, seja no plano dos preceitos de um agente, seja no plano da teoria de um filósofo moral, são fatores que decorrem exatamente da exatidão e plena determinação dos requisitos pelos quais uma ação vem a ver uma ação virtuosa no sentido estrito. Vejamos o seguinte texto:"De fato, delimitar com exatidão todas as coisas desse tipo não é fácil, pois elas têm muitas e variadas diferenças, tanto em relevância ou irrelevância, como também quanto ao que é belo e quanto ao que é necessário" 20

${ }^{20}$ Cf. $1164 b$ 22-30. 
Aristóteles diz que não é fácil delimitar com exatidão todos os fatores relevantes que definem a ação correta. Essa afirmação se situa, porém, no plano teórico: Aristóteles quer dizer que não é fácil delimitar uma teoria na qual os fatores relevantes sejam considerados a contento e com exatidão, bem como não é fácil delimitar um preceito universal (que se possa apresentar como válido para várias circunstâncias, não apenas para uma) para lidar com esses fatores relevantes. Mas por que não é fácil? Resposta verdadeira, mas trivial e, no meu entender, pouco esclarecedora consistiria em dizer que delimitar um preceito ou uma teoria não é fácil porque nossa razão é limitada, de modo que não temos capacidade de calcular todas as probabilidades envolvidas na contingência de cada circunstância singular de ação. É mais esclarecedor explicar a dificuldade em questão pelo outro lado: não pela fraqueza de nossa razão, mas pela determinação dos requisitos que fazem uma ação tornar-se virtuosa. Nossa faculdade da razão é a mesma, seja na técnica, nas ações ou nas ciências estritamente teóricas. No domínio da ação, no entanto, cada ação singular conta como ação virtuosa apenas se ela satisfizer uma série de requisitos que dizem respeito a fatores plenamente determinados, porque são fatores que envolvem coisas singulares, em circunstância de tempo e lugar bem precisas.

O que esse arrazoado permite esclarecer, assim, é o seguinte: uma ação virtuosa, em si mesma, é virtuosa pelo fato de que acertou o alvo, e acertar o alvo é uma metáfora que envolve o acerto e a exatidão de uma série articulada de fatores singulares. Nesse sentido, a ação virtuosa, enquanto ação virtuosa, requer exatidão, e se define como uma ação "exata": trata-se da exatidão no acerto de cada um dos fatores relevantes dos quais depende o caráter virtuoso da ação.

Esse ponto permite-nos entender de modo bem satisfatório o argumento de Aristóteles no trecho que consideramos (1106b 8-16). Há um pequeno problema filológico na reconstituição do argumento. Trata-se de saber o que conta como antecedente e o que conta como elucidação parentética. Sigo a edição de Bywater, na qual teríamos um argumento cujo antecedente seria constituído das seguintes premissas ${ }^{21}$ :

(i) todo conhecimento técnico perfaz bem seu produto considerando como alvo a mediedade (1106b 8-9);

21 Rowe e Taylor tomam o texto de Bywater. Irwin não usa parênteses em sua tradução, mas parece entender 0 argumento como no texto de Bywater. Zingano, 2008, p. 50, prefere 0 texto de Bekker e Susemihl. 
(ii) a virtude é melhor e mais exata que a técnica (1106b 14-15).

A conclusão que se poderia esperar seria a seguinte: também a virtude, então, "perfaz bem seu produto", isto é, realiza a ação virtuosa, considerando como alvo a mediedade. A conclusão, no entanto, é mais determinada:

(iii) "a virtude é boa acertadora da mediedade" (tou mesou stochastike) (1106a 15-16).

Diante do leitor provavelmente surpreso, ou indignado, devo, é claro, justificar a tradução de "stochastike" por "boa acertadora", e não por expressões bem mais amenas e cautelosas, como "tem em mira a mediedade" ou "tem como alvo a mediedade". Mas o ponto é simples. O verbo "stochazo" quer dizer, de fato, "mirar", "ter como alvo". Daí parece se seguir que o adjetivo "stochastikos" teria, como sentido imediato, "ser um mirador", ou "ser alguém que considera um alvo". Considere-se, no entanto, sob quais condições aplicaríamos a alguém o adjetivo "stochastikos". Suponha um fulano que passa tardes inteiras com seu arco, mirando o alvo, mas sem nunca dispará-lo. Fulano é tal que ele consegue passar horas focalizando o alvo com precisão, mas ele nunca dispara sua flecha. Alguém se sentiria autorizado a chamar tal fulano de "stochastikos"? Creio que qualquer pessoa sensata diria que o adjetivo em questão não seria bem aplicado a tal fulano, pelo simples fato de que a ação de mirar, longe de ser completa em si mesma, é orientada para a ação de disparar em direção ao alvo. Suponhamos, então, um segundo fulano, o qual também tem a capacidade de calibrar bem sua vista de modo a focalizar com precisão o alvo. Diferentemente do primeiro fulano, ele às vezes dispara sua flecha, mas ele erra o alvo em todas suas tentativas, embora tenha focalizado o alvo com precisão. Alguém talvez se sentisse autorizado a dizer que esse fulano é "stochastikos", pois ele é alguém que "mira o alvo" etc. No entanto, o que o adjetivo "stochastikos" introduz é a noção de alguém que é bom em mirar o alvo, mas bom em mirar o alvo no sentido de que, no mais das vezes, acerta o alvo, diferentemente do nosso segundo fulano. O que quero dizer é que acertar $o$ alvo em um número relevante de tentativas inclui-se entre as condições requisitadas para receber o adjetivo "stochastikos". Tal adjetivo não remete apenas à ação de mirar o alvo etc., mas remete a tal ação considerada sob o ponto de vista da finalidade a que ela atende, que é acertar o alvo. Afinal, esse é o sentido que Liddell \& Scott registram para "stochastikos": "skilful in aiming at, able to hit" (grifo meu). Não é preciso que, para ser chamado de "stochastikos", alguém sempre acerto o alvo. Mas o adjetivo carrega em si 
mesmo o requisito de que se acerte o alvo em número significativo de tentativas e, por isso, tal adjetivo não pode ser usado para designar nenhum dos dois fulanos que usei como exemplo22.

Meu ponto consiste em sugerir que, entendido desse modo, o argumento compactado em 1106b 8-16 contribui para compreender em que sentido a virtude moral seria "mais exata" do que a técnica. Se estou correto, Aristóteles considera, na conclusão (iii), que a virtude é uma disposição que não apenas mira a mediedade, mas acerta a mediedade em número significativo de tentativas. Ou seja: na conclusão ao argumento, Aristóteles já considera a virtude como uma disposição que, em número significativo de vezes, leva a cabo seu propósito, isto é, produz aquilo que, por sua própria natureza, deve produzir: ações virtuosas (no sentido estrito dessa expressão, delimitado em 1105a 28-33). Se é assim, pode-se esperar que, já na premissa (ii), a virtude tenha sido assumida sob a mesma perspectiva. A premissa (ii), portanto, não destaca o aspecto segundo o qual a virtude envolve uma coleção de enunciados a que se poderia chamar de "conhecimento moral do agente" (e que poderia ser comparado ao "conhecimento técnico do produtor"). A premissa (ii) considera a virtude do ponto de vista dos resultados que ela normalmente perfaz por sua própria essência. Nesse sentido, a premissa (ii), "a virtude é mais exata que a técnica” (1106b 14-15) deve ser entendida do seguinte modo: a virtude, na medida em que é tal que acerta o alvo, produz regularmente resultados que exigem a satisfação de requisitos singulares. Ora, esses requisitos singulares exigidos pelas ações virtuosas são mais numerosos e mais complexos do que os requisitos exigidos para a fabricação de produtos técnicos. Assim, a virtude, na medida em que produz regularmente resultados que exigem a satisfação de requisitos

\footnotetext{
22 Rowe traduz o passo 1106a 15-16 de modo bem acertado: "it will be effective at hitting upon what is intermediate", bem como Crisp: "is able to hit the mean". Não compreendo por que alguns tradutores insistem em minimizar a noção de acerto já contida no adjetivo, como fazem Irwin ("aim at what is intermediate"), Ross ("it must have the quality of aiming at the intermediate") e Zingano ("terá em mira 0 meio termo"). Ora, não é preciso que alguém considerado stochastikos seja tal que acerte 0 alvo 100\% das vezes. Mas é relevante que alguém reconhecido como stochastikos acerte 0 alvo em número bem significativo de tentativas. Além do mais, em 1106b 15-16, Aristóteles, longe de se referir a um agente virtuoso, está falando da virtude como causa que produz certos resultados (em comparação com a técnica). Ora, não é necessário que o agente virtuoso sempre acerte: se ela erra algumas poucas vezes, e erra por pouco, não deixará de ser considerado virtuoso (cf. 1109b 18-20). No entanto, quanto à virtude, enquanto disposição orientada para a produção de ações virtuosas no sentido relevante, podese dizer que a noção de acertar o alvo está definicionalmente incluída em seu conceito, pois acertar 0 alvo é o mesmo que praticar virtuosamente a ação virtuosa (do mesmo modo que se pode dizer que a construção de uma casa está definicionalmente incluída na arte oikodomike).
} 
singulares que são mais numerosos e mais complexos do que os requisitos exigidos para a fabricação de produtos técnicos, é mais exata que a técnica ${ }^{23}$.

Por essas razões, não julgo acertada a solução que Irwin pretende dar ao aparente paradoxo envolvido na afirmação de que a virtude moral é mais exata que a técnica. Irwin diz o seguinte: it [= virtue] differs from craft insofar as a craft is a capacity that can be used well or badly, whereas virtue is the direction of a capacity to the right use. Hence we may expect virtue to focus more precisely on the right end, and therefore (since such a focus requires aiming at the mean) to aim at the mean. ${ }^{24}$ Há várias objeções contra tal proposta. Em primeiro lugar, o contraste para o qual Irwin aponta dificilmente poderia ser caracterizado em termos de maior ou menor precisão. Na verdade, nem sequer é claro qual é o contraste ao qual Irwin remete: o que ele quer dizer ao afirmar que uma técnica pode ser usada bem ou mal? Se ele quer dizer que um médico, dotado da capacidade de curar, pode escolher, em dada circunstância, o fim incorreto, que é matar o paciente, não vejo de que modo isso poderia ser traduzido em termos de diferença de exatidão entre virtude e técnica. Por outro lado, se Irwin quer dizer que há, por exemplo, bons carpinteiros e maus carpinteiros, isso prova que há graus de precisão na própria técnica, mas isso não prova que a virtude seria mais exata que a boa carpintaria. Além do mais, pode-se dizer que há certos requisitos que mesmo um mau carpinteiro teria de satisfazer, pois, caso contrário, não seria chamado de "carpinteiro". Creio que, no contexto, o termo "técnica" é usado por Aristóteles para se referir à capacidade de produzir artefatos que satisfazem esses requisitos mínimos, que mesmo o mau carpinteiro teria de satisfazer. Trata-se de provar que a virtude seria mais exata do que essa técnica, que satisfaz os requisitos mínimos para a fabricação de seu produto. Irwin diz, além do mais, que é de se esperar que a virtude

\footnotetext{
${ }^{23}$ De nada vale dizer que "invertemos 0 argumento", tomando a conclusão como premissa e a premissa como conclusão. Essa suposta objeção seria uma objeção séria apenas se 0 argumento de Aristóteles pretendesse explicar que a virtude acerta 0 alvo porque é mais exata que a técnica, mas creio que 0 argumento de Aristóteles está longe de ter essa pretensão. Aristóteles quer apenas introduzir a tese de que a virtude acerta 0 alvo, e esse infere essa tese da premissa de que a virtude é mais exata que a técnica. Há implicação recíproca entre "a virtude é mais exata que a técnica" e "a virtude é boa acertadora da mediedade", mas há uma nenhuma pretensão de explicação de uma proposição pela outra. Havendo apenas implicação recíproca sem pretensão de explicação no sentido estrito, é óbvio que uma proposição pode ser provada pela outra, o que autoriza a interpretação que acabei de propor. Para a diferença entre implicação recíproca e explicação em sentido estrito, ver Segundos Analíticos 78a 26-38, 98b 2-24.

${ }^{24}$ Cf. Irwin, 1999, p. 198.
} 
"tenha mais precisamente em mira a mediedade". Ora, mesmo a técnica medíocre, que de certo modo erra o alvo no sentido de que produz um produto medíocre, teve em mira a "mediedade" (cf. 1106b 8-9) e falhou apenas na execução. A estratégia de Irwin, portanto, não dá conta de caracterizar de modo satisfatório a afirmação de que a virtude é mais exata que a técnica ${ }^{25}$.

25 Taylor, 2007, p. 103, recorre a Partes dos animais 639b 19-21, mas não creio que esse texto seja elucidativo a respeito do modo pelo qual a virtude moral seria mais exata que a técnica. A virtude moral nem sequer é mencionada em 639b 19-21. 


\section{Referências Bibliograficas}

BROADIE, S., \& ROWE, C. Aristotle: Nicomachean Ethics. Oxford: Oxford University Press. 2002.

IRWIN, T. Aristotle: Nicomachean Ethics, Indianapolis: Hackett. 1999.

ROSS, D. Aristotle: Nicomachean Ethics, in Barnes, J. (edd.), The Complete Works of Aristotle (The Revised Oxford Translation), Oxford: Oxford University Press. 1984.

TAYLOR. C. C. W. Aristotle: Nicomachean Ethics, Books II-IV, Oxford: Oxford University Press (Clarendon Aristotle Series). 2007.

ZINGANO, M. Aristóteles: Ethica Nicomachea I 13- III 8: Tratado da Virtude Moral. São Paulo: Odysseus. 2008.

E-mail: angioni.lucas@gmail.com

Recebido: abril/2009

Aprovado: junho/2009 